\title{
OS DIREITOS FUNDAMENTAIS SOCIAIS E O ESTADO PÓS-NEOLIBERAL
}

\section{FUNDAMENTAL SOCIAL RIGHTS AND THE STATE POST - NEOLIBERAL}

\section{RESUMO}

O presente trabalho tem como objetivo analisar se no Estado Pós-neoliberal os Direitos Fundamentais Sociais trabalhistas continuarão a existir. Para isso será feita uma explanação do que vem a ser o Estado e uma análise de seu percurso histórico desde o Estado Liberal até o Estado Neoliberal. Em seguida será discorrido sobre o surgimento, os conceitos e a importância dos Direitos Fundamentais e sobre a análise dos Direitos Sociais como Direitos Fundamentais. Ademais será verificada a necessidade da garantia dos Direitos Sociais em um possível Estado Pós-neoliberal, pois estes são Direitos humanos fundamentais. O método de abordagem utilizado na pesquisa é o dedutivo e a técnica utilizada de documentação é indireta, envolvendo pesquisa bibliográfica.

Palavras-Chave: Direitos Fundamentais Sociais. Estado. Pós-Neoliberalismo.

\begin{abstract}
This paper aims to analyze whether in the Post Neoliberal State the Fundamental Social Rights of Labor will continue to exist. For this purpose, an explanation of what the State becomes will be done and an analysis of its historical course from the Liberal State to the Neoliberal State, as well. It will then be discussed the rising of concepts and the importance of Fundamental Rights and on the analysis of Social Rights as Fundamental Rights. In addition, it will be verified the necessity of the guarantee of the Social Rights in a possible Post Neoliberal State, since these are fundamental Human Rights. The approach used in the research is the deductive and the technique used for documentation is indirect, involving bibliographic research.
\end{abstract}

Key-words: Social Fundamental Rights. State. Post- neoliberalism.

${ }^{1}$ Mestranda em Direito pela Universidade Federal de Santa Catarina, UFSC - (Brasil). -Professora Especialista da Faculdade Luciano Feijão (FLF). Coordenadora Adjunta do Curso de Direito da Faculdade Luciano Feijão. E-mail: ysmeniapontesadv@gmail.com

2 Pós-doutora em Direito pela Universidade Federal de Santa Catarina, UFSC, (Brasil). Professora da Graduação e Mestrado em Direito da Faculdade Christus, UNICHRISTUS. Advogada. E-mail: realbuquerque@yahoo.com 


\section{INTRODUÇÃO}

A globalização, na sua vertente neoliberal, visa cada vez mais proteger e disseminar o capitalismo como única forma capaz de organizar o modo de produção em sociedades complexas na qual se vive. Essa aldeia global traz em seu bojo uma ideologia segundo a qual o mercado livre é o único capaz de responder às expectativas de um mundo cada vez mais único e homogêneo em suas demandas. Ocorre que esse discurso escamoteia as crises pelas quais passa o capitalismo ao longo da sua história, principalmente nos dias atuais com a modernização da cadeia de produção, em que milhões de trabalhadores são sistematicamente excluídos do processo de produção em decorrência da introdução de novas tecnologias, a informatização, a robótica, a microeletrônica, a biotecnologia, ou seja, uma série de revoluções tecnológicas que, se não dispensa, pelo menos minimiza o trabalho humano na cadeia produtiva.

A crise do capitalismo tem gerado milhões de desempregos e espalhado a miséria pelo mundo. Cada vez mais a população mundial se pergunta para onde estamos caminhando, como fica a questão do trabalhador nesse novo contexto, de modo que se pergunta pela exequibilidade de tal modelo, abrindo espaço a um modelo que possa superar o neoliberalismo. Para isso o artigo irá analisar o que seria o Estado em suas várias roupagens; em seguida, demonstrar-se-ão os modelos que existiram, como também a sua evolução e a sua decadência.

Com as revoluções no mercado e as inovações nas relações de trabalho, o que se observa, hoje, é uma flexibilização dos direitos trabalhistas e a precarização do trabalho. Esse novo modo de relação trabalhista traz um grande risco para a preservação dos Direitos sociais, pois o Estado não está conseguindo intervir e a economia está ditando as regras não só do mercado, mas principalmente da maneira como a sociedade como um todo deve organizar-se. Numa palavra: ou o trabalhador se adequa ou está fora do mercado de trabalho.

A Constituição Federal de 1988 garante, no rol dos Direitos Sociais, os direitos trabalhistas, que são também direitos humanos e econômicos, à medida que a mesma Constituição garante moradia, lazer, alimentação e a busca por um emprego. Dessa 
forma, esses direitos devem permanecer resguardados pela Constituição, independentemente do novo modelo econômico que se adote. Muitos serão os desafios de um novo modelo e será preciso olhar para o passado para que não se incorra nos mesmos erros.

No Estado Liberal, a burguesia ascendente buscava a igualdade e a liberdade como forma de garantir o livre comércio e proteger seus contratos. No Estado Social o que se busca é algo bem maior; além da liberdade e da igualdade, busca-se a intervenção do Estado no mercado, nos espaços públicos, como garantia de acesso a todos aos serviços tidos como necessários a uma vida digna.

Findo o Estado do Bem-estar Social, emerge o Estado de Direito Democrático e com ele o neoliberalismo, que passou quase setenta anos para ser representado. Foi a Inglaterra o país a encarnar de modo mais sistemático a versão mais ortodoxa do modelo neoliberal, que teve seu auge no governo da primeira ministra Margaret Thatcher. Da Inglaterra esse modelo foi adotado paulatinamente em outros países.

O Brasil vive, hoje, um modelo neoliberal falido e o que se espera é a criação de um Estado Pós-neoliberal que garanta os Direitos Sociais em que o Estado possa intervir nos direitos sociais fortemente para evitar a precarização das relações trabalhistas. Diante dessa visão passa-se a discorrer sobre o tema.

1. Do Estado Liberal ao Estado Neoliberal

Para que se possa compreender a importância do Estado na garantia dos Direitos Fundamentais, faz-se necessária uma análise do que vem a ser o Estado e suas diversas formas de apresentação. Logo serão explanados, aqui, os modelos de Estado Liberal, o Estado do Bem-Estar social e o Estado neoliberal chegando até ao que já é considerado como Estado Pós-Neoliberal. Alguns autores já começaram a trabalhar a ideia de um Estado Pós-neoliberal. O que se busca averiguar é se nesse novo modelo seria possível a permanência dos Direitos Sociais trabalhistas garantidos na Constituição Federal de 1988. Para a realização dessa pesquisa, faz-se necessária a análise do que seria o Estado no decorrer dos séculos.

A palavra Estado já foi recepcionada pelos povos de diversas maneiras. Se pararmos para pensar desde Santi Romano, a definição de Estado, para esse autor, sofre 
constantes alterações. O direito faz parte do próprio Estado, e, enquanto instituição, o Estado seria a entidade jurídica, a qual só é possível realizar-se através do direito. Para o estudioso italiano, um dos elementos essenciais do Estado é o povo, e é por meio da coletividade que se dá o Estado. Nesse caso, o povo seria uma espécie de junção, ou seja, de unidade em que há várias pessoas e suas individualidades. Nesse sentido, o que vem diferenciar o Estado dos demais entes é o povo, a soberania. Logo o Estado é soberano e seria uma fonte jurídica. Para Romano, todo e qualquer agrupamento de pessoas é uma instituição pelo simples motivo de elas serem organizadas. Contudo, percebe-se que para o autor o direito é instituição, o Estado também, logo, o Estado é direito. Como relata o autor,

\footnotetext{
sem dúvida, o Estado se auto-limita quando põe o seu ordenamento jurídico, mas não existe algum momento em que ele não seja limitado, justamente por ser, desde a sua origem, um ordenamento. Sua autolimitação pode ser somente uma limitação a mais. Portanto, a lei nunca é, como frequentemente se acredita, o começo do direito. É, ao contrário, uma complementação ao direito precedente (na hipótese que este tenha lacunas) ou uma modificação do mesmo. (ROMANO, 2008, p.117)
}

Como várias formas de definição de Estado, temos a de Grotius, que o define como aquele que tem o mesmo objetivo do direito natural, pois envolve a proteção dos direitos subjetivos. Para ele, “o Estado é uma união perfeita de homens livres associados para gozar da proteção das leis e para sua utilidade comum” (p.88, 2005). Entretanto, não é o Estado apropriado para penalizar aqueles que não cumprem a lei e sim o próprio contrato apoiado no direito natural. Para o autor, o direito natural serve para regular a convivência humana, que, segundo ele, tem o fundamento racional-natural. Diz que a vida, a dignidade da pessoa humana e a propriedade pertencem ao direito natural. Nesse caso, o povo continua sendo o ponto alvo do Estado mesmo que visto de outra maneira.

Maquiavel é o primeiro escritor ou cientista político que utiliza a palavra Estado no sentido de instituição, que administra um território e possui pessoas. Dessa forma, ele é conhecido como o criador do Estado moderno. Maquiavel é o precursor da concepção do Estado moderno no qual o ponto principal é a centralização do poder político. O Estado, com essa definição, só aparece a partir do século XVI. Para 
Maquiavel, a manutenção da ordem se dá através das mãos do príncipe e não por meio das mãos dos cidadãos. A soberania é consequência da força do poder político. Maquiavel é considerado o pai do Estado Moderno, como dito, mas também o primeiro, depois dos gregos a vislumbrar uma forma de democracia, que seria a representativa. Dallari (2013, p.59) diz que: "a denominação de Estado (do latim status=estar firme), significando situação permanente de convivência e ligada à sociedade política, aparece pela primeira vez em "O Príncipe" de Maquiavel, escrito em 1513, passando a ser usada pelos italianos sempre ligada ao nome de uma cidade independente, como, por exemplo, stato de Firenze".

Para Montesquieu (1985), no modelo de Estado idealizado, o monarca centraliza o poder em suas mãos e acaba por confundir o Estado com a sua pessoa, por isso, não existe a diferenciação entre as esferas públicas e privadas. Uma célebre frase do rei Luís XIV da França ilustra bem esse período: L’État cést moi (o Estado sou eu).

Ao Estado natural falta, diz Locke (1991, p. 264), uma lei estabelecida, firmada, reconhecida por todos; um juiz conhecido e indiferente com autoridade para solucionar os conflitos; um poder que apoie e sustente a decisão, quando justa. Assim é quase impossível de se encontrarem homens que vivam dessa maneira, que respeitem a equidade e a justiça. Portanto, a insegurança e o risco constante fazem com que se abandone essa liberdade natural. Por isso, Locke sugere a criação da instituição como pacto social que irá gerir todas essas dificuldades e garantirá todos os direitos já presentes no Estado natural, como relata a citação a seguir:

$$
\begin{aligned}
& \text {... e para impedir a todos os homens que invadam os direitos dos outros e que } \\
& \text { mutuamente se molestem, e para que se observe a lei da natureza, que } \\
& \text { importa na paz e na preservação de toda a humanidade, põe-se, naquele } \\
& \text { estado, a execução da lei da natureza nas mãos de todos os homens... } \\
& \text { (LOCKE, 1991, p. 218). }
\end{aligned}
$$

Nesse pacto social, as leis devem ser aprovadas pelo mútuo consentimento dos participantes do pacto e julgado por juízes imparciais como demonstra a passagem que trata também do que se pode definir como poder político, senão vejamos:

O poder político é o que cada homem tendo no estado de natureza cedeu às mãos da sociedade e dessa maneira aos governantes, que ela instalou sobre si, com o encargo expresso ou tácito de que seja empregado para o bem e para a 
preservação da mesma... Assim, o objetivo e a medida desse poder, quando nas mãos de todos no estado de natureza, consistindo na preservação de todos da sua sociedade - isto é, de todos os homens em geral - , não pode ter outro fim ou medida quando nas mãos do magistrado que não preservar os membros dessa sociedade na vida, liberdade e posse de que gozam; não podendo assim ser poder absoluto e arbitrário sobre a vida e a fortuna dos homens, que terão de ser preservadas... Esse poder tem origem somente no pacto e assentimento, e consentimento mutuo dos que compõem a comunidade. (LOCKE, 1991, p. 284-285).

O Estado consiste, para Locke, na supremacia do povo, ele consegue libertar o povo da tirania dos reis.

Diante de todas as definições de Estado, o autor Darcy Azambuja (2008, p.18) diz que: "O Estado, portanto, é uma sociedade, pois se constitui essencialmente de um grupo de indivíduos unidos e organizados permanentemente para realizar um objetivo comum". O que se percebe nesse percurso é que existem "teorias que afirmam a formação natural do Estado." (também chamada teoria organicista ou organicismo) e "Teorias que sustentam a formação contratual dos Estados" (denominada teoria mecanicista ou mecanicismo) (DALLARI, 2013, p.62).

Diante da passagem inicial da definição de Estado, é salutar perceber que, a partir do momento em que foi assinada a paz de Westfália em 1648, é que emergem as manifestações do ente estatal. Com isso, teríamos inicialmente cinco modelos de Estado, quais sejam: O Estado de Polícia, O Estado de Direito, O Estado Social de Direito, O Estado Totalitário e o Estado Democrático de Direito (BASTOS, 2004, p. 156). Para Bastos (2004, p. 159), no Estado de Polícia há uma centralização de poder nas mãos do rei apesar de o rei ter uma pequena limitação, como diz o autor (2004, p. 160): “A única criação dessa época que coíbe muito parcialmente o poder absoluto do príncipe é o fisco. Por essa entidade jurídica, deixa-se de lado o Estado e o príncipe como responsável pelo patrimônio que era trasladado para a titularidade do aludido fisco". Assim, teria o príncipe o seu poder limitado apenas ao fisco, podendo nas demais áreas atuar livremente. Para finalizar o Estado de Polícia, ou seja, o absolutismo, Bastos (2004, p.160) diz que “a ideia de polícia é responsável por fazer residir no príncipe o 
sujeito legitimado a promover o desenvolvimento material, intelectual e artístico. Era a própria civilização que, por suas mãos, caminharia mais celeremente".

O Estado de Direito emerge no fim do século XVIII e início do século XIX. Esse modelo surge para atender às necessidades da burguesia, que não aceitava mais o absolutismo ou Estado de Polícia. Segundo Bastos (2004, p. 161), o Estado de Direito "é a ideia de um Estado mínimo que de forma alguma interviesse na vida dos indivíduos, a não ser para o cumprimento de suas funções básicas; fora isso deveriam viger as regras do mercado, assim como a livre contratação". Nesse sentido, o Estado de Direito deve proteger os cidadãos e está subordinado ao Direito. A função do Direito passa a ser, além de regular a vida das pessoas, a de regular também o Estado. A partir daí é evidente o princípio da legalidade, pois se passa a definir o que o Estado pode fazer e o que não pode. Com o Estado de Direito, "dá-se início então a um processo de democratização do Estado que irá culminar com o Estado democrático de Direito" (BASTOS, 2004, 163). Foi a Revolução Francesa, ato da burguesia contra o absolutismo monárquico na França, que com os seus ideais de liberdade e igualdade trouxe mudanças significativas, pois, em 1789, foram declarados os Direitos do Homem, de modo que o homem passa a participar das discussões do Estado, por meio da democracia. A partir daí, o direito positivo passa a imperar, e o poder soberano é da Nação. Para Bastos (2004, p. 166):

\footnotetext{
As maiores conquistas da Revolução Francesa, sem dúvida nenhuma, foram a institucionalização das liberdades individuais e os avanços para a igualdade entre os homens, além da proclamação da soberania do povo e da necessidade de um regime representativo baseado na escolha dos governantes pelo povo e na descentralização.
}

Com as ideias da Revolução Francesa, emerge o Estado Liberal, no qual a burguesia quer a universalização dos mercados. Nesse sentido, a burguesia retratava a vontade popular, que era sua própria vontade, em busca da liberal-democracia. Bonavides (2001, p.61) diz que: "a burguesia, com o longo tirocínio de sua pugna contra o absolutismo, passara a desconfiar do poder. E no Estado-liberal-democrático, erguido pelo constitucionalismo pós-revolucionário, o princípio liberal triunfara indiscutivelmente sobre o princípio democrático". Para Raniere, 
Não se pode desvincular a doutrina liberal da democracia representativa do século XIX e inicio do século XX. No pensamento liberal clássico, a liberdade política, expressa pela participação dos cidadãos no Legislativo, era a única forma de assegurar as demais liberdades. Logo, um Estado que tinha por finalidade garantir as liberdades individuais contra o poder político exigia, necessariamente, participação de indivíduos e grupos nas definições políticas. (2013, p.259)

O modelo de Estado liberal surgiu como a busca pela liberdade em que o povo quer se libertar da tirania do Estado. Esse modelo busca cada vez mais se desvincular do absolutismo e demostra que a burguesia, além de possuir o poder econômico, busca o poder político. A base do Estado Liberal é o liberalismo econômico. O Liberalismo, "no início, voltava-se contra a imposição de crenças religiosas, filosóficas e científicas, durante a revolução holandesa. Já nas revoluções seguintes: inglesa, americana e francesa, opunha-se ao absolutismo político e à sociedade estamental do ancien régime, que sufocava a mobilidade e a liberdade social” (MACEDO, 2006, p.531).

Em 1917, com a revolução russa, o Estado liberal cede espaço ao Estado Social ou, como muitos chamam, o Estado do Bem-Estar Social ("Welfare State"), um dos motivos que levaram a permanência do Estado social foram as crises econômicas que trouxeram uma grande recessão e desemprego "demonstrando ser os mecanismos autoreguladores de economia insuficiente (sic) para promover harmonicamente $\mathrm{o}$ desenvolvimento da riqueza nacional" (BASTOS, 2004, p.166). Com isso, passa a ser necessária a presença do Estado para tentar corrigir erros provenientes da própria estrutura inerente ao modelo liberal.

Importante ressaltar que "o poder no Estado Liberal era exercido no sentido de limitar a utilização dos direitos em benefício da segurança. Agora, no Estado social, o fim passa a ser outro" (BASTOS, 2004, p.168). Na verdade, o Estado social é o resultado das transformações pelo qual passou o Estado Liberal. Para Bonavides (2001, p.186):

Quando o Estado, coagido pela pressão das massas, pelas reivindicações que a impaciência do quarto estado faz ao poder político, confere, no Estado constitucional, ou fora deste, os direitos do trabalho da previdência, da educação, intervém na economia como distribuidor, dita o salário, manipula a 
moeda, regula os preços, combate o desemprego, protege os enfermos, dá ao trabalhador e ao burocrata a casa própria, controla as profissões, compra a produção, financia as exportações, concede crédito, institui comissões de abastecimento, provê necessidades individuais, enfrenta crises econômicas, coloca na sociedade todas as classes na mais estreita dependência de seu poderio econômico, político e social, em suma, estende sua influência a quase todos os domínios que dantes pertenciam, em grande parte, à área de iniciativa individual, nesse instante o Estado pode, receber com justiça a denominação de Estado Social.

Percebe-se que o Estado Social busca o equilíbrio político no desenvolvimento social. Ele tenta garantir direitos individuais, mas também regula o mercado e seu comportamento. No modelo de Estado Liberal, o que se buscava era garantir as liberdades para que os indivíduos fossem livres e iguais. Já no Estado social, a busca é pela intervenção do Estado em vários setores, tendo como propósito a busca por melhorias na vida da sociedade.

Dando continuidade à análise dos cinco tipos de Estado, passa-se a estudar o Estado Totalitário. Mas antes se faz imprescindível dizer que o Estado social não se confunde com socialismo, que com ele coexiste e supera o Estado Liberal e nos dizeres de Bonavides (2001, p. 203) "compadece com o totalitarismo como, também, com a democracia". O Estado totalitário não se confunde com o Estado autoritário, ou seja, ele tem todas as manifestações da vida social e se envolve desde o poder político ao econômico. Com o surgimento de ideologias como o fascismo e o nazismo e o total controle da vida das pessoas inclusive controlando a opinião pública, perde-se assim o grande ideal da democracia, que é o princípio da liberdade. Para Bastos (2004, p. 172), “O Estado Totalitário diz respeito, pois, aos limites da atuação do Estado. É um dos extremos a que o Estado pode chegar em matéria do exercício do poder". Visivelmente esse modelo se opõe ao modelo liberal, pois no totalitarismo o Estado intervém na economia e até mesmo no que os indivíduos poderão consumir.

Como dito, no Estado totalitário surgem ideologias e uma delas foi o fascismo, que "se caracterizou por ser um sistema de governo autoritário, em que a monopolização da representação política era exercida por um único partido político de massa, que era organizado hierarquicamente". Nesse modelo, os direitos individuais 
eram esquecidos, o fascismo seria uma ditadura aberta da burguesia que não queriam as instituições democráticas. "O Estado fascista foi criado por Benito Mussolini, na Itália, em 1922, sendo o marco inicial do denominado totalitarismo de direita" (BASTOS, 2004, p.174). Os primeiros países a adotarem o fascismo foram a Itália e a Alemanha.

Já o nazismo emerge para combater o comunismo e o liberalismo democrático "pode-se dizer que o nazismo se desenvolveu "à sombra das instituições democráticas, sob a égide da Constituição de Weimar" (BASTOS, 2004, p.175). Esse modelo existiu na Alemanha sob o comando de Hitler entre 1933 e 1945 e não concordava com o socialismo, a pequena burguesia apoiava o movimento com medo do que poderia acontecer com o avanço do comunismo. Tinham como meta a existência de uma única raça, a ariana, e a conquista de novos territórios. Desse modo, buscavam o crescimento econômico nos mercados mundiais.

Assim como o Estado Liberal foi superado pelo Estado Social, o Estado do Bem-Estar social foi superado, em alguns países, pelo que se conhece Neoliberalismo. O neoliberalismo surge logo após a segunda guerra mundial na Europa e na América do Norte, locais onde o capitalismo predominava (ANDERSON, 2012, p.09). Foi uma ação contra o estado de Bem-estar social. O livro "O Caminho da Servidão" de Hayek traz uma mensagem muito forte sobre o Estado social democrático alegando ser este uma espécie de servidão moderna. O neoliberalismo não conseguiu se firmar rapidamente, demorando, para isso ocorrer, uns 70 anos. Mas em 1979, na Inglaterra, com Margaret Thatcher emerge o primeiro país capitalista a adotar o modelo neoliberal. Depois da Inglaterra vieram os Estados Unidos, em seguida, a Alemanha, a Dinamarca e posteriormente os outros países do norte da Europa ocidental, exceto Suécia e Áustria (ANDERSON, 2012, p. 11).

No modelo de economia neoliberal, o que se busca é o desenvolvimento econômico das empresas não tendo nenhum tipo de preocupação com o Estado. Para o modelo neoliberal, o próprio mercado consegue chegar a um equilíbrio desejado. Assim tira do estado a preocupação ou a responsabilidade com as questões econômicas e deixa que o próprio mercado se autorregule. Para esse artigo, o que interessa com relação a esse modelo é fazer perceber que o neoliberalismo enfraquece os Direitos Sociais dos 
trabalhadores, pois sempre que é a própria economia que se regula o Estado não consegue intervir e muito menos evitar a flexibilização trabalhista, que é uma maneira de precarização das relações de trabalho.

O próximo tópico buscará demonstrar que os Direitos Sociais são Direitos Fundamentais e não poderiam por isso sofrer flexibilizações que coloquem os trabalhadores em situação de servidão só que servidão aos empresários as empresas que determinam o mercado e a economia.

2. Dos Direitos Fundamentais Sociais

Os Direitos Fundamentais emergem no século XVII como expressão das revoluções liberais que dão origem ao Estado Democrático de Direito. Antes o que se tinha era, por exemplo, a Declaração do Povo de Virgínia, a Declaração dos Direitos do Homem e do Cidadão em 1789 e a Convenção Interamericana dos Direitos Humanos, ou seja, o Pacto de São José da Costa Rica.

Foi na segunda dimensão dos Direitos Fundamentais que os Direitos Sociais emergiram. Os impactos da industrialização e os vários problemas econômicos vivenciados após a revolução industrial na Inglaterra propulsionaram os trabalhadores a reivindicarem melhorias nas condições de trabalho, como redução de carga horária, horas extras e outros. O povo não suportava mais tanta exploração "Enquanto uns viviam no luxo, a grande maioria da população passava fome, estava desempregada ou morria por falta de cuidados médicos" (MARMELSTEIN, 2008, p.48). Logo o Estado já não conseguia mais controlar a classe operária, e eles estavam fortemente organizados. Com isso começavam a aparecer as primeiras manifestações contra o modelo explorador.

O surgimento dos Direitos Fundamentais se dá com o intuito de controlar o Estado e seu poder. Como já foi falado no tópico anterior, o Estado na maioria das vezes foi considerado como um soberano que detinha o total poder. Os Direitos Fundamentais são considerados direitos históricos, pois não podem simplesmente atender a todas as gerações, por isso são considerados mutáveis. Outra característica dos Direitos fundamentais é que eles são também considerados universais, e essa 
universalidade é garantida na Constituição Federal de 1988 bem como personalíssimos e irrenunciáveis.

O que esse trabalho considera relevante é que não há dúvidas de que os Direitos Sociais são Direitos Fundamentais e por isso protegidos pelo princípio da vedação do retrocesso. Na Constituição Federal de 88 , o artigo $1^{\circ}$ - que trata dos fundamentos do nosso Estado Democrático de Direito, no seu inciso IV - prevê os valores sociais do trabalho e a livre iniciativa. Para Sarlet (2014, p.21), isso tem "a mesma relevância e hierarquia axiológica, evidenciando um compromisso com a simetria entre capital e trabalho, no mínimo, contudo, espancando qualquer leitura parcial e sectária”. Da mesma forma, o artigo 170, VIII, da Constituição Federal, que trata da busca pelo pleno emprego, diz que (Constituição Federal texto digital): “A ordem econômica, fundada na valorização do trabalho humano e na livre iniciativa, tem por fim assegurar a todos existência digna, conforme os ditames da justiça social, observados os seguintes princípios: VIII - busca do pleno emprego". Nesse sentido são princípios de ordem econômica os Direitos Sociais. No mesmo sentido, o art. 193 da CF diz (Constituição Federal texto digital): "A ordem social tem como base o primado do trabalho, e como objetivo o bem-estar e a justiça sociais" Logo não restam dúvidas de que os diretos dos trabalhadores brasileiros são Direitos Fundamentais sociais e econômicos resguardados pela Carta Magna.

Para corroborar com esse entendimento, Sarlet (2014, p.22) afirma que:

Uma primeira constatação que se impõe e que resulta já de um superficial exame do texto constitucional, é a de que o Poder Constituinte de 1988 acabou por reconhecer, sob o rótulo de direitos sociais, um conjunto heterogêneo e abrangente de direitos (fundamentais), o que, sem que se deixe de admitir a existência de diversos problemas ligados a uma precária técnica legislativa e sofrível sistematização (que, de resto, não constituem uma particularidade do texto constitucional, considerando o universo legislativo brasileiro) acaba por gerar consequências relevantes para a compreensão do que são, afinal de contas, os direitos sociais como direitos fundamentais.

e-ISSN: 2525-9865 | Curitiba | v. 2 | n. 2 | p. 01 - 18 | Jul/Dez. 2016. 
Diferentemente da Espanha e de Portugal, ${ }^{3}$ que não arrolaram os direitos dos trabalhadores como direitos sociais, o Brasil assim o fez. Então, desde 1988, esses direitos devem ser considerados como Direitos Humanos e Fundamentais, pois na própria Constituição é garantido o direito à moradia e ao lazer. Sobre isso explana o artigo 6": "São direitos sociais a educação, a saúde, a alimentação, o trabalho, a moradia, o transporte, o lazer, a segurança, a previdência social, a proteção à maternidade e à infância, a assistência aos desamparados, na forma desta Constituição" (Constituição Federal online) direitos esses considerados humanos. Tal condição é adotada, inclusive, pelo Supremo Tribunal Federal.

Os Direitos Sociais, previstos no art. $6^{\circ}$ da $\mathrm{CF}$, e os direitos dos trabalhadores, previstos no art. $7^{\circ}$, são considerados Direitos Fundamentais. O problema surge quando se envolvem as questões econômicas e o constante desejo em se precarizar esses direitos. Essa é uma grande preocupação diante do cenário mundial econômico vivido, pois, como defende Ferrajoli (2015), a economia é que move o mundo e, consequentemente, os Direitos. O Estado não consegue mais intervir e, com isso, constata-se o modelo neoliberal. O que se questiona é: será que os Direitos Sociais resistirão a um Estado Pós-neoliberal? No próximo tópico será analisado o que seria esse modelo de Estado e o que se espera dele.

3. Os Direitos Sociais dos Trabalhadores em uma Era Pós-neoliberalista

Falar em uma era Pós-neoliberal é algo desafiador há mais de vinte anos. Fala-se em um possível modelo pós-neoliberal tendo em vista que o Capitalismo e o Socialismo restam findados. Mas a primeira pergunta que emerge é: será que o pós-neoliberalismo já está ocorrendo? Para Goran Therborn (2012, p. 182),

o pós-neoliberalismo será uma situação política e social em que os desafios e as tarefas da justiça social, os direitos sociais e econômicos de todos os seres humanos, os problemas planetários do meio ambiente e a questão da arquitetura do ambiente social estarão no centro do discurso político. Dado que o neoliberalismo como tal é uma superestrutura do capital atual, o pósneoliberalismo deverá ser outra nova situação política e ideológica.

3 No texto original de Portugal os direitos dos trabalhadores eram considerados Direitos Sociais, econômicos e culturais, mas depois foram realocados no título dos direitos, liberdades e garantias. (SARLET, 2014, p.23) 
Para o autor, deverá surgir uma nova ideologia com outra roupagem. Acredita-se que se esteja diante de um neoliberalismo sério e é preciso que a esquerda também seja séria para que possa garantir os direitos sociais. Para ele, a esquerda tem três desafios, o primeiro seria, diz o autor: "necessitamos de análises empíricas rigorosas sobre os novos mecanismos de acumulação, sobre os processos de mudança cultural e de destruição social" (2012, p.182). Para que esse primeiro desafio possa ser enfrentado, é preciso detectar o que causa a miséria e a injustiça social e a partir daí tentar encontrar um modelo que se adeque a essa transformação. O segundo desafio da esquerda para o autor "é reconhecer o valor da capacidade de gerenciamento, ao mesmo tempo em que devemos aprender a manejar a produção, a administração e a direção macroeconômica e macropolítica" (2012, p. 182). Esse desafio busca não colocar a justiça social do lado oposto da estabilidade monetária. O terceiro e último desafio é "ampliar a sensibilidade artística na arte política da comunicação de massas" (2012, p.183). Logo, para o autor, é preciso que a esquerda seja forte e séria para que consiga encontrar um meio termo para as categorias que formam os trabalhadores e a categoria que formam as empresas.

A sensação que se tem é de que neoliberalismo não funcionou e de que não há modelo imutável, o capitalismo é um modelo fracassado que trouxe milhares de desempregos e construiu milhões de miseráveis pelo mundo. Chega a hora de se pensar em um novo modelo que perpassa o Estado Neoliberal, modelo esse que prima pela justiça social, mas que não seja o já fracassado Estado de Bem-Estar Social. Para Borón (2012, p.186), “o pós-neoliberalismo é, ainda, uma etapa em construção” mesmo esse autor tendo pensado isso há mais de vinte anos, ainda assim, é um fato contemporâneo, pois ainda não se sabe se estamos vivendo em um Estado pós-neoliberal. Quero veementemente acreditar que não, ainda não estamos em um novo modelo de Estado, pelo ao menos no Brasil. É preciso muito mais para superarmos um Estado neoliberal que deixa como herança "uma sociedade profundamente desagregada e distorcida, com gravíssimas dificuldades em se construir do ponto de vista da integração social e com uma agressão permanente ao conceito e à prática da cidadania" (BORÓN, 2012, p. 187).

Na luta contra o neoliberalismo, Perry Anderson, em seu artigo intitulado "Além do Neoliberalismo" (2012, p.197), fala da necessidade de se conhecer o neoliberalismo 
para conseguir criar um novo modelo que seria pós-neoliberal sem trazer resquícios daquilo que deu errado. Para ele, o neoliberalismo tem três lições que devem ser observadas, a primeira seria "não ter nenhum medo de estar absolutamente contra a corrente política de nosso tempo", a segunda "não transgredir em ideias, não aceitar nenhuma diluição de princípios" e a terceira lição é "não aceitar nenhuma instituição estabelecida como imutável”. Nesse sentido nenhuma instituição é intocável.

Para Perry Anderson, surge o seguinte questionamento, como o neoliberalismo poderá deixar de existir? É preciso muito trabalho da esquerda, que deverá trabalhar os valores e ressaltar o princípio da igualdade, a garantia de emprego para todos a distribuição de cultura, enfim, alargar as redes de proteção dos Direitos Sociais (ANDERSON, 2012, p. 200). Evidente que se deve resguardar a propriedade, evitando assim as privatizações excessivas e a democracia que os neoliberais tanto tentam derrubar.

O Estado pós-neoliberal tem um grande desafio pela frente que é garantir os Direitos Fundamentais Sociais. O que se percebe, hoje, é a fragmentação do trabalho e a sua precarização em vários setores. Para exemplificar essa situação, temos como exemplo a terceirização, que provavelmente poderá até ser realizada por atividades fins e não mais apenas as atividades meio. Outro exemplo é o teletrabalho, ou seja, o funcionário sai da empresa mais continua responsável por atender ligações, receber e responder e-mail e mais atualmente whatsapp. O empregado trabalha integralmente dentro e fora da empresa: essa é uma maneira de precarização, tendo em vista que o que está em jogo é a saúde do trabalhador, pois ele fica refém da empresa. Em um modelo Pós-neoliberal, seria preciso uma posição forte do Estado para evitar esta precarização, algo que não se percebe atualmente. O queE existe é uma globalização neoliberal extremamente capitalista que só visa ao lucro. E como já dito anteriormente a economia se autorregula e se autodetermina definindo o mercado de trabalho sem que para isso o Estado possa intervir. Em um Estado Pós-neoliberal, é preciso que o Estado evite este tipo de postura.

\section{CONCLUSÃO}


Os Direitos Fundamentais não poderão retroagir nem mesmo em um novo modelo. Diante de tudo que foi explanado nesse artigo o que se espera é que, em um Estado Pós-neoliberal, os Direitos Sociais sejam resguardados e que o Estado volte a ter força, podendo intervir nas relações trabalhistas com o intuito de preservar esses direitos. Hoje o Estado não está conseguindo intervir como deveria. No modelo Neoliberal, a própria economia decide o rumo ao qual os Direitos devem seguir, ou seja, as leis são alteradas constantemente para satisfazer o mercado, e, com isso, as relações de trabalho são cada vez mais fragmentadas e precarizadas. O teletrabalho, a terceirização, as cooperativas são criadas com o simples intuito de burlar a lei, fazendo a contratação de trabalhadores sem resguardar os seus direitos trabalhistas. Isso se torna cada dia mais comum e é por esse e por outros motivos que ainda não se acredita em um novo modelo. Ainda estamos presos às amarras do capitalismo selvagem que não quer a presença do Estado e que se possível privatizará todos os espaços públicos possíveis como os hospitais, as praças, as escolas, os presídios e tantos outros. Essa é a concepção da globalização-neoliberal: é esse o modelo que ainda vivenciamos.

Há mais de vinte anos se acredita em um novo Estado que ainda não pairou sobre o nosso território, um Estado que consiga harmonizar as questões econômicas com as questões sociais. Nesse artigo foi levantado o seguinte questionamento: Será que os Direitos Sociais resistirão a um Estado Pós-neoliberal e como o Estado Neoliberal deixará de existir dando espaço para um novo modelo de Estado? A resposta que se pode verificar é que ainda estamos em um momento de transformação e ainda não se pode afirmar nada. Mas a ideia é que se percorra o melhor caminho olhando para trás e não cometendo os erros do passado buscando um Estado presente que lute pelos direitos do seu povo assim como todo Estado dever ser. Portanto, deve o Estado primar pelos direitos constitucionais, lutar para a manutenção dos valores e garantir o Estado Democrático de Direito.

Chega-se ao fim desse artigo na expectativa de que emerja um modelo ideal em que os Direitos Sociais além de constarem no texto constitucional possam ser realmente sentidos pelo povo. Para isso deverá existir emprego para todos, e a miséria do mundo deverá deixar de existir. Esse é o desejo que me fortalece e faz acreditar em um modelo 
diferente do Estado de Bem-Estar Social, pois esse não galgou sucesso como já demonstrado, mas um modelo harmonioso que consiga fazer com que os preceitos da Constituição Federal sejam verdadeiramente sentidos por seu soberano, ou seja, pelo seu povo.

\section{REFERÊNCIAS BIBLIOGRÁFICAS}

ANDERSON, Perry. Balanços do Neoliberalismo. In: Pós-neoliberalismo: As Políticas Sociais e o Estado Democrático. (org.) SADER, Emir; GENTILI, Pablo. São Paulo: Paz e Terra. 2012, p. 9-23.

Além do neoliberalismo. . In: Pós-neoliberalismo: As Políticas Sociais e o Estado Democrático. (org.) SADER, Emir; GENTILI, Pablo. São Paulo: Paz e Terra. 2012, p. 197-202.

AZAMBUJA, Darcy. Teoria geral do Estado. 4.ed. rev,.ampl. e atual. São Paulo: Globo, 2008.

BASTOS, Celso Ribeiro. Curso de Teoria do Estado e Ciência Política. $6^{\text {a }}$ ed. São Paulo: Celso Bastos, 2004.

BONAVIDES, Paulo. Do Estado Liberal ao Estado Social. $7^{\text {a }}$ ed. São Paulo: Malheiros, 2001.

BORÓN. Atilio. O pós-neoliberalismo é uma etapa em construção. In: Pósneoliberalismo: As Políticas Sociais e o Estado Democrático. (org.) SADER, Emir; GENTILI, Pablo. São Paulo: Paz e Terra. 2012, 185-196.

BRASIL. Constituição Federal. Disponível em:

http://www.planalto.gov.br/ccivil_03/constituicao/constituicaocompilado.htm.

Acessado em 04 de junho de 2016.

DALLARI, Dalmo de Abreu. Elementos de teoria geral do Estado. 32.ed. São Paulo, 2013.

FERRAJOLI, Luigi. A democracia através dos direitos: o constitucionalismo garantista como modelo teórico e como projeto político. Trad. Alexander Araújo de Souza e outros. São Paulo: Revista dos Tribunais, 2015. 
GROTIUS, Hugo. O direito da guerra e da paz. Tradução de Ciro Mioranza. v.1. 2 ed. Ijuí: Ed. Unijuí, 2005.

LOCKE, Jonh. Segundo Tratado sobre o governo. Tradução de E. Jacy Monteiro. 5 ed. São Paulo: Nova Cultural, 1991. (Os pensadores)

MACEDO, Ubiratan Borges de. Liberalismo. In. BARRETO, Vicente de Paulo (Coord.). Dicionário de Filosofia do Direito. São Leopoldo: UNISINOS, 2006.

MACHIAVELli, Nicoló. O Príncipe. Tradução de Lívio Xavier. 5 ed. São Paulo: Nova Cultural, 1991. (Os pensadores)

MARMELSTEIN, George. Curso de Direitos Fundamentais. São Paulo: Atlas, 2008.

MONTESQUIEU, Charles de Secondat (Barão de). O Espírito das Leis. 3. ed. São Paulo: Abril cultura, 1985.(os pensadores)

RANIERI, Nina Stocco. Teoria do Estado: do Estado do Direito ao Estado Democrático do Direito. Manole, 01/2013. VitalSource Bookshelf Online.

ROMANO, Santi. O Ordenamento Jurídico. Tradução de Arno Dal Ri Júnior. Florianópolis: Fundação Boiteux, 2008.

SARLET, Ingo Wolfgang. Os Direitos dos Trabalhadores como Direitos Fundamentais na Constituição Federal Brasileira de 1988. In. Diálogos entre o direito do trabalho e o direito constitucional: Estudos em homenagem a Rosa Maria. Weber. (coord.) SARLET, Ingo Wolfgang; MELLO FILHO, Luiz Philippe Vieira; FRAZÃO, Ana de Oliveira. São Paulo: Saraiva, 2014.. 